OPEN ACCESS

Edited by:

Alejandro Lazo-Langner, University of Western Ontario, Canada

Reviewed by:

Uday Deotare,

University of Western Ontario, Canada

Ioannis Mitroulis,

Democritus University of

Thrace, Greece

*Correspondence:

Simona W. Rossi

Simona.rossi@unibas.ch

tThese authors have contributed equally to this work

Specialty section:

This article was submitted to Hematology,

a section of the journal

Frontiers in Medicine

Received: 18 September 2019 Accepted: 08 April 2020 Published: 28 April 2020

Citation:

Stoikou M, van Breda SV, Schäfer G,

Vokalova L, Giaglis S, Plattner A,

Infanti L, Holbro A, Hahn S, Rossi SW

and Buser A (2020) G-CSF Infusion

for Stem Cell Mobilization Transiently

Increases Serum Cell-Free DNA and

Protease Concentrations.

Front. Med. 7:155.

doi: 10.3389/fmed.2020.00155

\section{G-CSF Infusion for Stem Cell Mobilization Transiently Increases Serum Cell-Free DNA and Protease Concentrations}

\author{
Maria Stoikou ${ }^{1 \dagger}$, Shane V. van Breda ${ }^{1 \dagger}$, Günther Schäfer ${ }^{1}$, Lenka Vokalova ${ }^{1}$, \\ Stavros Giaglis ${ }^{1}$, Alexandra Plattner ${ }^{2}$, Laura Infanti ${ }^{2}$, Andreas Holbro ${ }^{2}$, Sinuhe Hahn ${ }^{1}$, \\ Simona W. Rossi ${ }^{1 *+}$ and Andreas Buser ${ }^{2+}$ \\ ${ }^{1}$ Department of Biomedicine, University of Basel and University Hospital of Basel, Basel, Switzerland, ${ }^{2}$ Blood Transfusion \\ Service, Swiss Red Cross Basel, Basel, Switzerland
}

G-CSF for stem cell mobilization increases circulating levels of myeloid cells at different stages of maturation. Polymorphonuclear cells (PMNs) are also mobilized in high numbers. It was previously reported that G-CSF primes PMNs toward the release of neutrophils extracellular traps (NETs). Since NETs are often involved in thrombotic events, we hypothesized that high G-CSF blood concentrations could enhance PMN priming toward NET formation in healthy hematopoietic stem cell donors, predisposing them to thrombotic events. However, we found that G-CSF does not prime PMNs toward NETs formation, but increases the serum concentration of cell-free DNA, proteases like neutrophils elastase and myeloperoxidase, and reactive oxygen species. This could possibly create an environment disposed to induce thrombotic events in the presence of additional predisposing factors.

Keywords: G-CSF, stem cell mobilization, PMN, MPO, NE, ROS, cell-free DNA, NETs

\section{INTRODUCTION}

Granulocyte colony-stimulating factor (G-CSF) is playing an essential role as a colony-stimulating factor during hematopoiesis. G-CSF stimulates proliferation and differentiation of hematopoietic stem cells (HSC) (1), differentiation of precursor cells into mature PMNs, and the release of mature granulocytes and hematopoietic stem cells from the bone marrow (2). The latter has led to the widespread use of G-CSF (3) for the mobilization of HSC for transplant purposes $(4,5)$. Findings from the last 20 years indicate that HSC mobilization with G-CSF is associated with an increased hypercoagulable state and therefore a higher risk for thrombotic events (6).

PMNs play a leading role in innate immunity (7); they are rapidly recruited to sites of inflammation where they phagocytose, degranulate, or generate NETs (8). The release of NETs is an active and rapid process that leads to a specific form of PMN cell death, called NETosis (9). NETs are composed of nuclear DNA decorated with histones and granular proteins such as neutrophil elastase (NE) and myeloperoxidase (MPO). One key regulator of NET formation in the citrullination of Histone $\mathrm{H} 3$ mediated by the enzyme PAD4. It was described that NETs can promote thrombosis (10) since histones $\mathrm{H} 3$ and $\mathrm{H} 4$ enhance platelet recruitment by activation of factor XII (11). Moreover, NE, MPO and reactive oxygen species (ROS) seem to regulate the clotting cascade and promote coagulation by cleavage and oxidation of anticoagulants; tissue factor pathway 
inhibitor (TFPI) and thrombomodulin (TM) (12). Recently it was observed that increased levels of circulatory G-CSF contributed to the regulation of NETosis during pregnancy (13), which is also associated with increased risk for thrombosis.

The goal of our study was to analyse the occurrence and dynamics of NET formation in healthy stem cell donors at the time of stem cell collection and follow-up.

We observed that circulating PMNs mobilized after G-CSF application present markers of immaturity, correlate with high cell-free DNA and increased protease content. This effect was of short duration, with all parameters returning back to baseline 1-month post-G-CSF infusion.

\section{MATERIALS AND METHODS}

\section{Donors}

Allogeneic peripheral stem cell donors were asked to participate in the study. Donor eligibility was assessed according to internal policies and in compliance with the current FACTJACIE standards (https://www.ebmt.org/jacie-standards). G-CSF (Neupogen ${ }^{\circledR}$, Amgen) was applied at a dose of $10 \mu \mathrm{g} / \mathrm{kg}$ body weight divided into two doses daily (total: eight injections) subcutaneously, beginning 5 days before HSC harvest.

This study was approved by the ethical committee of Northern and Central Switzerland (2015-00191).

\section{Samples Collection and PMN Isolation}

Samples were collected from HSC donors and healthy agematched controls at various time points; 3-4 weeks prior to GCSF administration (visit A); at the time of HSC harvesting (visit B); 1 and 3 months post apheresis (visit C and D).

Whole blood was collected into EDTA- and silicone-coated tubes (Sarstedt), and analyzed by a Advia (Siemens) for complete blood cell counts. Plasma and serum were collected and processed as described previously (13). Shortly: PMN were isolated by Dextran-Ficoll density centrifugation (13) (purity $>95 \%)$.

\section{PMNs Analysis}

FACS: PMNs $\left(5 \times 10^{5}\right)$ were suspended in FACS-buffer (PBS, $10 \% \mathrm{FBS}, 0.1 \% \mathrm{NaN}_{3}$ ) and stained for $30 \mathrm{~min}$ at $\mathrm{RT}$ using CD66B-FITC (Biolegend), CD34-PE (Caltag) and CD61-AF647 (Biolegend). Acquisition: Accuri-C6-Plus (Becton Dickinson). PMN (10,000 events) were analyzed using Flow Jo (version 10).

Late apoptosis: isolated neutrophils were incubated in 100 $\mu l$ annexin binding buffer containing phycoerythrin-conjugated Annexin V (Annexin V-PE) and 7-amino-actinomycin D (7AAD) (Annexin-V Apoptosis Detection Kit, ThermoFisher Scientific) for $15 \mathrm{~min}$ at room temperature (RT) in the dark. After incubation, $400 \mu \mathrm{l}$ annexin binding buffer was added, and samples were measured immediately on a BD Accuri ${ }^{\mathrm{TM}}$ C6 FACS (BD Biosciences). The Annexin $\mathrm{V}-\mathrm{PE}^{+} / 7-\mathrm{AAD}^{+}$populations were taken as measurements of late apoptotic cells. Data were analyzed using FlowJo v10 software (FlowJo, LLC).

NETs quantification: PMN $\left(2.5 \times 10^{4}\right)$ were incubated with $0.2 \mu \mathrm{M}$ SytoxGreen (Life Technologies), $37^{\circ} \mathrm{C}, 5 \% \mathrm{CO}_{2}, 3 \mathrm{~h}$ (13). PMA (25 nM) was used as the positive control. Results are displayed as mean fluorescence intensity (MFI) measured using a Synergy H1-Hybrid-Reader (Biotek). Excitation: 485 $\mathrm{nm} / \mathrm{emission:} 535 \mathrm{~nm}$.

\section{Serum Analysis}

Histone/DNA complexes was performed using the "Human Cell

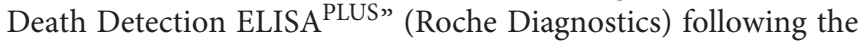
manufacturing protocol (14). NE concentration was performed using the "Elastase/a1-PI Complex ELISA-Kit" (Calbiochem) following the manufacturer protocol (14).

MPO concentration was measured using the "Hycult Biotech ELISA-Kit" following the manufacturer protocol (14).

CitH3 concentration was measured using "Citrullinated Histone H3 (Clone 11D3) ELISA-Kit” (Cayman) following the manufacturer protocol.

NE activity was measured in serum incubated with the elastase substrate, N-methoxysuccinyl-Ala-Ala-Pro-Val-7amido-4-methylcoumarin $\left(0.25 \mathrm{mM}\right.$, Sigma) for $30 \mathrm{~min}$ at $37^{\circ} \mathrm{C}$, $5 \% \mathrm{CO}_{2}$ in the dark. The reaction product was analyzed at 360/455 nm (15).

PAD4 western blotting: protein extraction using RP1 Buffer (Macherey Nagel), 1\% $\beta$-Mercaptoethanol (Sigma) and purification using Nucleo Spin (Macherey Nagel). Antibodies: rabbit anti-PAD4 (Abcam ab59965; 1:1,000), human antiHRP (Cell Signaling; 1:2,000) and SuperSignal West Pico Chemiluminescent Substrate (ThermoScientific), Mouse anti- $\beta$ Actin (Sigma-Aldrich) as a control. Protein quantification was performed using Image Lab Software (version 5.2.1).

ROS measurement: $3.0 \times 10^{4} \mathrm{PMNs}$ were incubated with $25 \mu \mathrm{M}$ DCFDH-DA (Sigma-Aldrich). Fluorescence was recorded at 0 , and 30 min using a Biotek Synergy H1 Hybrid plate Reader and expressed as relative fluorescence units (RFU).

Statistic: All data is represented as Mean \pm SEM. Comparisons between HSC donors visits was performed using ANOVA with Tukey's post-test correction. Data processed using GraphPad Prism version 8.0 (GraphPad Software Inc.).

\section{RESULTS}

\section{NET Released Is Stable Upon G-CSF Mobilization Treatment}

Twenty healthy stem cell donors who were undergoing HSC collection by apheresis after mobilization with G-CSF were included in the study. Demographic and clinical variables of the study population are presented in Table 1. Blood cell counting indicated a striking increase in PMN-like cells and PBMCs at the time of apheresis, which returned to control levels 1-month postdonation (Figures 1A,B). Analysis for the PMN marker CD66b and the stem cell marker CD34 indicated that a high proportion of the PMNs at the time of apheresis were of an early hemopoietic developmental stage (Figure 1C).

The formation of PMNs and platelet complexes is an essential parameter indicating the possible initiation of clotting. We observed that the number of platelets (Figure 1D) remained constant throughout the four visits. However, the percentage of PMNs positive for the platelet marker CD61 increased at visit $\mathrm{B}$ but with high variability between donors (Figure 1E). This 
TABLE 1 | Demographic and clinical variables of the study population.

\begin{tabular}{lcccccc}
\hline Blood parameters & \multicolumn{2}{c}{ Visit A \pm SEM } & \multicolumn{2}{c}{ Visit B \pm SEM } & \multicolumn{2}{c}{ Visit C \pm SEM } \\
\hline Hb g/l & 150 & 2.6 & 139.7 & 2.19 & 137.3 & 7.78 \\
Tc G/l & 277 & 14 & 240.7 & 15.19 & 278.4 & 20.71 \\
Creatinine $\mu \mathrm{mol} / \mathrm{l}$ & 75 & 2.7 & 80.6 & 4.06 & & \\
ASAT U/l & 27 & 1.8 & 32.9 & 2.43 & \\
ALAT U/l & 28 & 4.1 & 28.8 & 6.56 & \\
CRP mg/l & 4.6 & 1.5 & 17.0 & 3.32 & \\
LDH U/l & 209 & 5.6 & 518.8 & 33.9 & \\
CD34/ $\mu$ l & & & 99.9 & 11.89 & \\
& & & & & \\
\end{tabular}

increase reverted to baseline levels at later visits indicating a normalization between PMNs and platelet interactions.

Due to the expression of CD61 on PMNs the aggregation between platelets and PMNs as described in Zarbock et al. (16), could prime PMN toward NET formation. Thus, PMN NETosis was measured by staining with Sytox. At visit B, NET formation was lower compared to the baseline and reached baseline levels at visit $\mathrm{C}$ and $\mathrm{D}$ (Figure 1F). This suggests that circulating PMNs at time of HSC donation after G-CSF exposure undergo less spontaneous NETosis than at any other time points. No differences between the different groups in Sytox intensity were measured if the cells were stimulated in presence of PMA (Figure 1F).

A key feature of pro-NETotic PMNs priming is the of citrullination of histone 3 (CitH3) mediated by PAD4. A slightly lower PAD4 expression was observed at visit $\mathrm{B}$ compared to visit $\mathrm{C}$ and D (Figure 1G). Similarly, the expression of CitH3 (Figure 1H) was decreased at visit $\mathrm{B}$ and reached baseline levels at visit $C$ and $D$. This data is in line with the decrease in spontaneous NETosis at visit $\mathrm{B}$, matching the high amounts of immature PMNs. At the same time the late apoptosis of PMN, that could also be a source of free DNA in the serum, did not result in different percentage of dying cells (Figure 1I) between the analyzed time points.

\section{Cell-Free DNA, MPO, NE, and ROS Are Increased in Serum Upon G-CSF Mobilization Treatment}

Other factors that could induce injuries in vessels and platelet aggregation are PMN cell-free DNA, proteases MPO and NE, as previously described (17-21). Therefore, we studied the concentration of cell-free DNA, MPO and NE in the serum of donors. At visit $\mathrm{B}$, a significantly higher serum concentration of cell-free DNA (Figure 2A), MPO (Figure 2B), and NE (Figure 2C) were measured compared to all other visits (all panels left). The concentration of cell-free DNA, MPO and $\mathrm{NE}$ were normalized to the median PMN cell number (Figures 2A-C, all panels right) to evaluate the ability of each PMN to release cell-free DNA, MPO and NE. We observed that PMNs extrude cell-free DNA, MPO, and NE at the same pace throughout the visits. Our results show that both NE activity (Figure 2D) and degranulation of MPO at visit B are decreased per cell number, reinforcing the hypothesis that probably immature circulating PMNs are not efficient in degranulation or NET formation.

As recently observed in pregnant women that G-CSF promotes PMN priming and ROS production (13), we examined the oxidative stress in our donor cohort. PMNs at visit B had a higher basal ROS secretion than controls (Figure 2E). ROS levels returned to the baseline already after 1 month. These features were more pronounced in PMN cultured for an additional $30 \mathrm{~min}$, suggesting that the production of ROS is altered upon G-CSF treatment.

\section{DISCUSSION}

This study shows that HSC mobilization with G-CSF increases the concentration of cell-free DNA, of PMN-derived proteases and ROS in serum. This effect is transient and the measured parameters returned to baseline levels in 1-month posttreatment, suggesting the existence of a window of susceptibility to thrombotic events in predisposed subjects.

Like most growth factors and cytokines, G-CSF results in modulation of immune cell composition, cytokine profiles and immune cell response (22) in the donor. As well, in the recipient of the bone marrow transplantation, as summarized in Deotare at al. higher $\mathrm{CD} 34^{+}$cell doses, derived from G-CSF application, lead to better recovery of neutrophils and platelets. With related bone marrow transplant, there is no apparent association of $\mathrm{CD}^{+}{ }^{+}$cell dose with chronic GvHD, but with unrelated bone marrow, higher $\mathrm{CD}_{3} 4^{+}$cell dose does seem to result in improved survival. Functional damage to the host marrow microenvironment through prior therapy and the malignant disease itself cannot be overcome by either increasing stem cell dose or using a graft with different stem cell composition (23).

Accordingly, we observe an overall increased cell number in peripheral blood of the donor, with PMN levels rising 10 times from baseline at the time of HSC collection. This increased cell number was due to the mobilization of immature PMNs as seen by the co-expression of CD66b and CD34. Although not entirely mature, about $50 \%$ of the circulating neutrophils did show a co-expression of CD61, indicating the possibility of aggregation between platelets and neutrophils. As described in Stakos et al. and Zarbock et al. this aggregation could lead to the activation of the NETotic pathway $(16,17)$. Another previous study proposed that the G-CSF administration could as well induce the activation of endothelial cells and the coagulation pathway, which could lead to a prothrombotic condition in stem cell donors (24). Recently Fuchs et al. (10) reported that also NETs, perfused with blood, could stimulate platelets to adhere, aggregate and promote thrombus formation. In that study, NET integrity, meaning the presence of histones on DNA-NET, was considered essential in this process because treatment with DNase and heparin (which avidly binds histones) abrogated their effect. Our study in human pregnancy did show as well a direct effect of G-CSF on the ability of PMN to release NET (13), therefore, we hypothesized that high dose G-CSF could induce spontaneous NET release, that in turn could induce thrombotic events in predisposed 
A

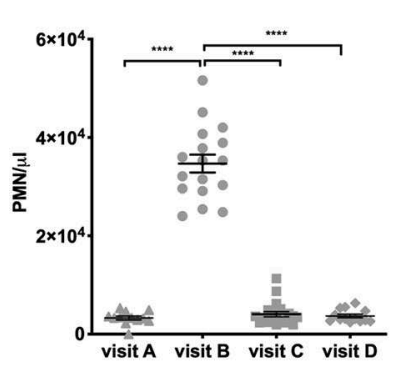

B

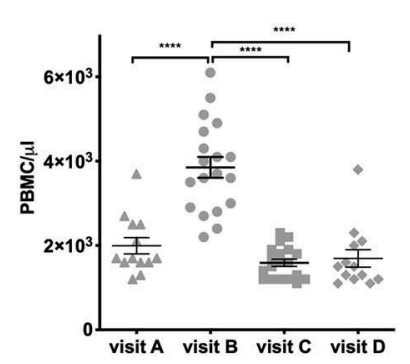

C

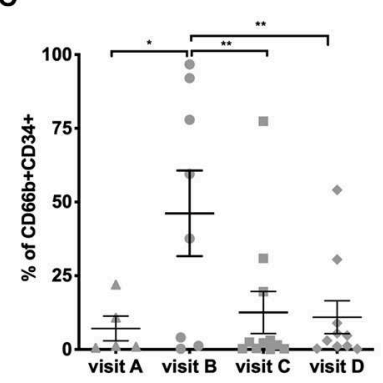

D

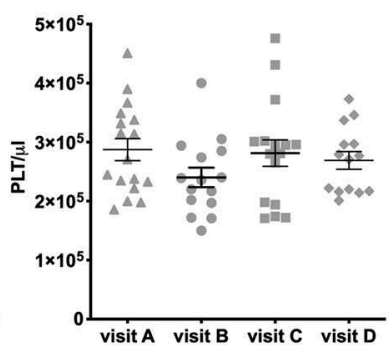

E
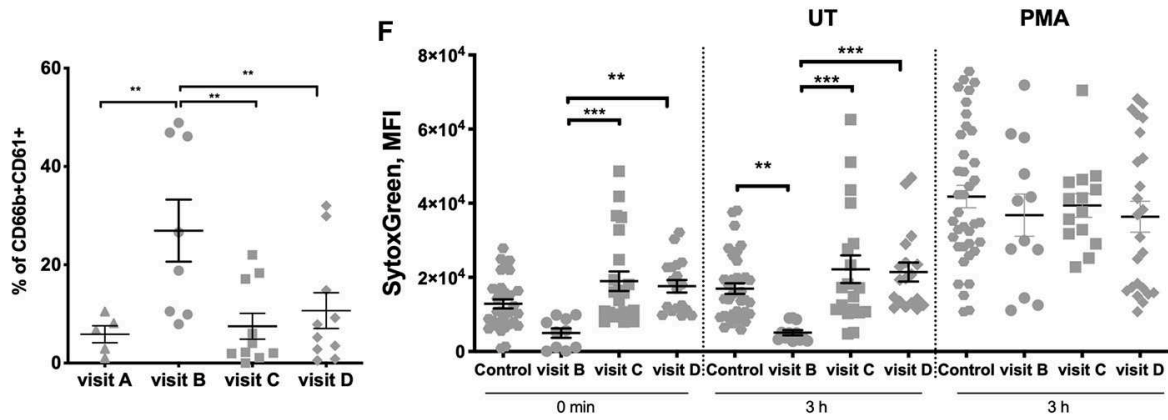

G

H

I
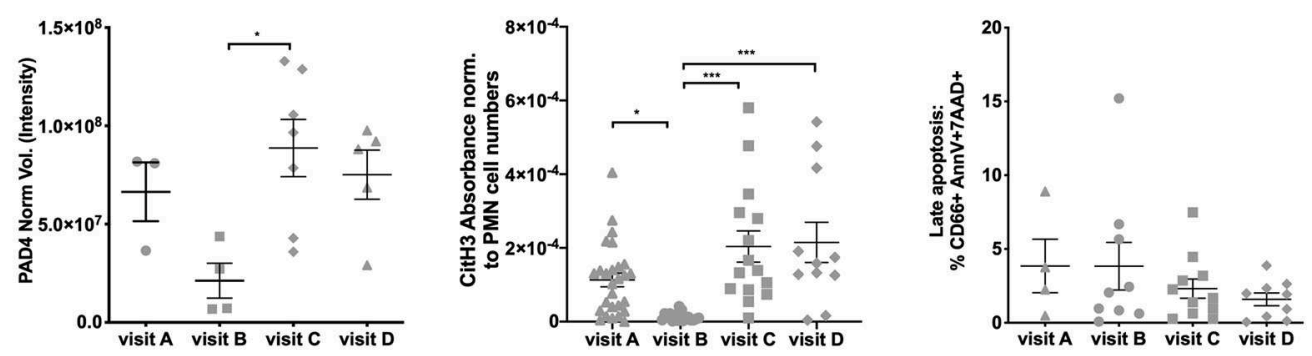

Visit A: 3-4 weeks prior to G-CSF administration, Visit B: at the time of HSC harvesting Visit C: one month post apheresis, Visit D: three months post apheresis

FIGURE 1 | Donor PMN population characteristics and NET formation ability. (A) Number of PMN per $\mu$ l blood of all donors. (B) PBMC numbers per $\mu$ I blood. (C) Percent expression of CD66b and CD34 on isolated PMN. (D) Number of Platelets per $\mu \mathrm{l}$ blood of all donors. (E) Percent expression of CD66b and CD61 on isolated PMN. (F) Spontaneous and PMA induced NETosis measured using Sytox Green DNA staining of freshly isolated PMN and after $3 \mathrm{~h}$ incubation. This assay is performed with the same amount of cells per visit. (G) PAD4 expression measured from $3 \times 10^{6}$ per visit using western blots. (H) CitH3 Absorbance measured in serum from donors at the different visits and normalized to PMN cell numbers. (I) Late apoptosis (\% of total PMNs number) measured in isolated PMNs using Annexin V and 7AA-D. ( $\left.{ }^{*} P<0.05,{ }^{* *} P<0.01,{ }^{* * *} P<0.001,{ }^{* * * * *} P<0.0001\right)$.

subjects. However, we observed that spontaneous neutrophil NET release was decreased at the time of donation and returned to control levels in 1 month after treatment. This reduced capacity to spontaneously NET formation was also mirrored by the expression of citH3 and PAD4.

Not only the spontaneous release of NET characterize the activity of PMN, but also other parameters have to be considered concerning a possible modification of the blood environment. Interestingly, we detected a 10 times higher concentration of cellfree DNA in the serum of donors after G-CSF mobilization; the origin of this cells-free DNA is still a matter of inquiring since apoptosis was not increased at visit B (data not shown). It was previously shown that increased levels of cell-free DNA in sepsis impaired fibrinolysis by inhibiting plasmin-mediated fibrin degradation (25). Another report showed that elevated levels of cell-free DNA in septic patients increased thrombin generation by activating the intrinsic pathway of blood coagulation (24). We are therefore tempted to speculate that higher cell-free DNA concentration could eventually modify the blood environment toward a predisposition to thrombotic events. However, other factors should be considered, for example the release of proteases, like, MPO and NE, which were observed in several previously published works [some examples are listed here (17-21)]. We measured also, in this case, higher concentrations of MPO 


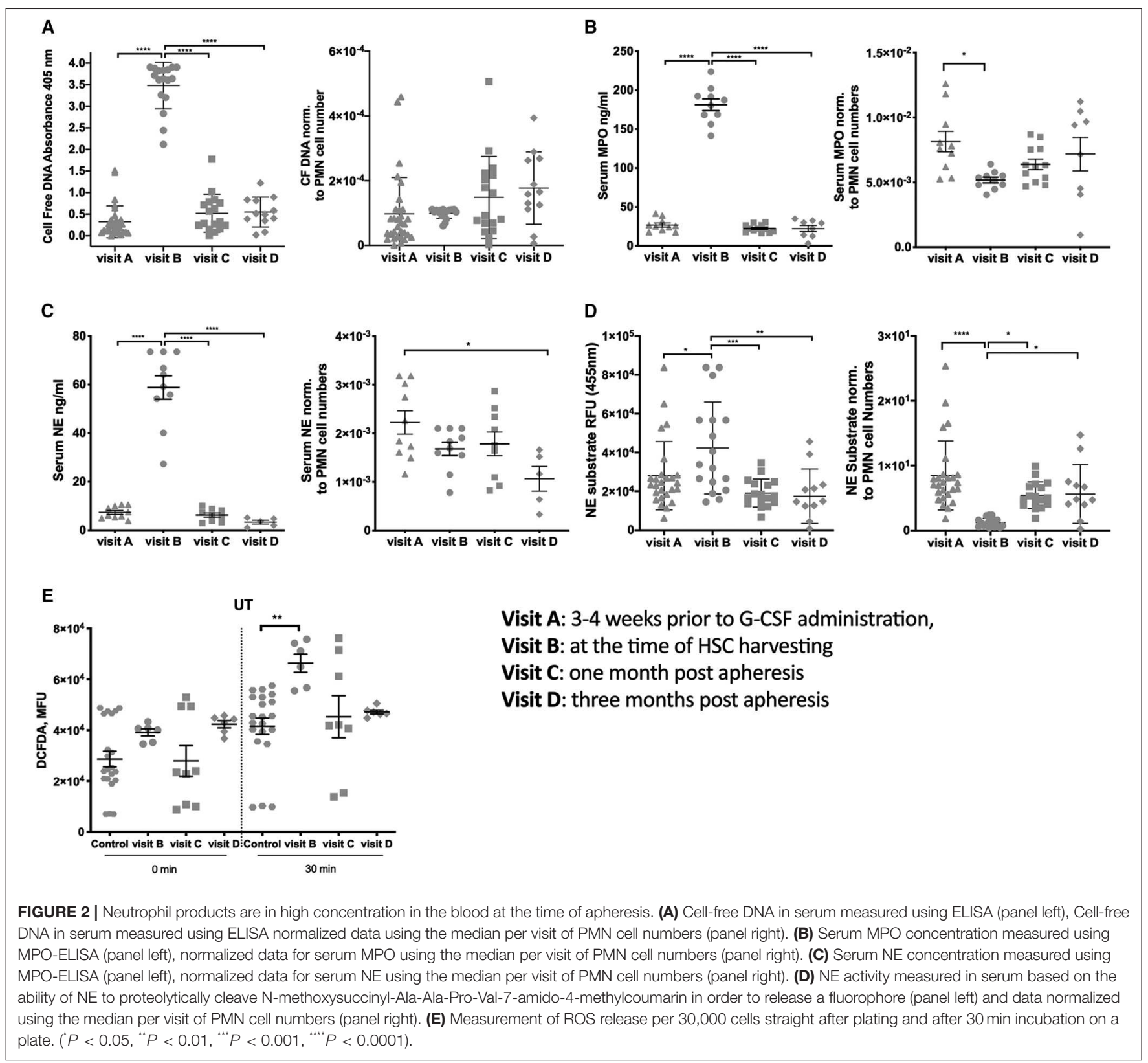

and NE in serum at donation that resume control levels 1month post-treatment.

It is important to mention that if those concentrations were normalized to the number of PMNs in the blood, the secretion of MPO and NE per cell was the same as in the other time points. This indicates that the total PMN population was not more active or prone to release DNA and proteases. The increased concentration in the serum is the consequence of high numbers of PMNs circulating in the blood and their ability to degranulate. We, therefore, propose that G-CSF creates a transient state of increased risk for hypercoagulability due to the increased concentration of cell-free DNA and proteases in the blood of HSC donors. On the other hand, thrombotic events remain infrequent, suggesting that other factors could contribute to it or prevent it.It was described that ROS could inhibit whole blood aggregation (26) and we could measure increased ROS at the time of donation. It has to be mentioned that in the work of Demers et al., performed in mice, in the presence of G-CSF, neutrophils were more sensitive to NET formation, in particular, upon encountering a "second hit," such as low-grade infection and extracellular DNA that is generated in animals with cancer, predisposing them to thrombosis (27). This observation is extremely important, since also in our case high amount of DNA are circulating in the blood of the donor for a limited time, possibly predisposing them, in case of a secondary trigger, like an infection, to a thrombotic event.

We recognize the following limitations of the study: first of all the number of recruited patients/donors is relatively low for a comprehensive study on PMNs behavior, however, since no difference was measured in the NET formation, we 
are confident that the information we deliver is valuable. Second, not all samples for each time point were included in the presented analysis: for every samples we did run a technical control, if this was resulting in activated PMNs, we did excluded the donor sample from the analysis to exclude a technical error. Third, it would be important to study the interactions between all the immune cells circulating in the blood at time of G-CSF infusion, since high number of PMNs could influence the phenotype and functionality of other immune cells. It would also be interesting to investigate the correlation between neutrophils protease activity due to the increased PMNs presence in the blood and HSC mobilization from the bone marrow niches. Further investigations to better understand the pathophysiology of thromboembolic events in GCS-F mobilized donors to identify a subject at risk are needed.

\section{DATA AVAILABILITY STATEMENT}

All datasets generated for this study are included in the article.

\section{REFERENCES}

1. Micallef IN, Stiff PJ, Stadtmauer EA, Bolwell BJ, Nademanee AP, Maziarz RT, et al. Safety and efficacy of upfront plerixafor plus G-CSF versus placebo plus G-CSF for mobilization of CD34(+) hematopoietic progenitor cells in patients $>=60$ and $<60$ years of age with non-Hodgkin's lymphoma or multiple myeloma. Am J Hematol. (2013) 88:1017-23. doi: 10.1002/ajh.23561

2. Falanga A, Marchetti M, Evangelista V, Manarini S, Oldani E, Giovanelli $S$, et al. Neutrophil activation and hemostatic changes in health donors receiving granulocyte colony-stimulating factor. Blood. (1999) 93:250614. doi: 10.1182/blood.V93.8.2506

3. Ehninger A, Trumpp A. The bone marrow stem cell niche grows up: mesenchymal stem cells and macrophages move in. J Exp Med. (2011) 208:421-8. doi: 10.1084/jem.20110132

4. Motabi IH, DiPersio JF. Advances in stem cell mobilization. Blood Rev. (2012) 26:267-78. doi: 10.1016/j.blre.2012.09.003

5. Greenbaum AM, Link DC. Mechanisms of G-CSF-mediated hematopoietic stem and progenitor mobilization. Leukemia. (2010) 25:211-7. doi: 10.1038/leu.2010.248

6. Anderlini P, Champlin RE. Biologic and molecular effects of granulocyte colony-stimulating factor in healthy individuals: recent findings and current challenges. Blood. (2008) 111:1767-72. doi: 10.1182/blood-2007-07-097543

7. Hahn S, Giaglis S, Chowdury CS, Hösli I, Hasler P. Modulation of neutrophil NETosis: interplay between infectious agents and underlying host physiology. Semin Immunopathol. (2013) 35:439-53. doi: 10.1007/s00281-013-0380-X

8. Brinkmann V, Reichard U, Goosmann C, Fauler B, Uhlemann Y, Weiss DS, et al. Neutrophil extracellular traps kill bacteria. Science. (2004) 303:15325. doi: 10.1126/science.1092385

9. Fuchs TA, Abed U, Goosmann C, Hurwitz R, Schulze I, Wahn V, et al. Novel cell death program leads to neutrophil extracellular traps. J Cell Biol. (2007) 176:231-41. doi: 10.1083/jcb.200606027

10. Fuchs TA, Brill A, Duerschmied D, Schatzberg D, Monestier M, Myers DDJ, et al. Extracellular DNA traps promote thrombosis. Proc Natl Acad Sci USA. (2010) 107:15880-5. doi: 10.1073/pnas.1005743107

11. Semeraro F, Ammollo CT, Morrissey JH, Dale GL, Friese P, Esmon NL, et al. Extracellular histones promote thrombin generation through plateletdependent mechanisms: involvement of platelet TLR2 and TLR4. Blood. (2011) 118:1952-61. doi: 10.1182/blood-2011-03-343061

12. Engelmann B, Massberg S. Thrombosis as an intravascular effector of innate immunity. Nat Rev Immunol. (2013) 13:34-45. doi: 10.1038/nri3345

13. Giaglis S, Stoikou M, Chowdhury CS, Schaefer G, Grimolizzi F, Rossi SW, et al. Multimodal regulation of NET formation in pregnancy: progesterone

\section{ETHICS STATEMENT}

The studies involving human participants were reviewed and approved by Ethical committee of Northern and Central Switzerland (2015-00191). The patients/participants provided their written informed consent to participate in this study.

\section{AUTHOR CONTRIBUTIONS}

$\mathrm{AH}, \mathrm{LI}, \mathrm{AP}$, and $\mathrm{AB}$ recruited the donor, discussed the manuscript, and organized foundings. MS, SB, GS, LV, SG, SH, and SR processed the samples, analyzed the data wrote, and discussed the manuscript.

\section{FUNDING}

This work was financed by a grant of the Regional Blood Transfusion Service, Swiss red Cross, Basel.

antagonizes the Pro-NETotic effect of estrogen and G-CSF. Front Immunol. (2016) 7:565. doi: 10.3389/fimmu.2016.00565

14. Stoikou M, Grimolizzi F, Giaglis S, Schäfer G, van Breda SV, Hoesli IM, et al. Gestational diabetes mellitus is associated with altered neutrophil activity. Front Immunol. (2017) 8:1749. doi: 10.3389/fimmu.2017.00702

15. Rochael NC, Guimarães-Costa AB, Nascimento MTC, DeSouza-Vieira TS, Oliveira MP, Souza LFGE, et al. Classical ROS-dependent and early/rapid ROS-independent release of neutrophil extracellular traps triggered by leishmania parasites. Sci Rep. (2015) 5:18302. doi: 10.1038/srep 18302

16. Zarbock A, Polanowska-Grabowska RK, Ley K. Platelet-neutrophilinteractions: linking hemostasis and inflammation. Blood Rev. (2007) 21:99-111. doi: 10.1016/j.blre.2006.06.001

17. Stakos DA, Kambas K, Konstantinidis T, Mitroulis I, Apostolidou E, Arelaki $\mathrm{S}$, et al. Expression of functional tissue factor by neutrophil extracellular traps in culprit artery of acute myocardial infarction. Eur Heart J. (2015) 36:1405-14. doi: 10.1093/eurheartj/ehv007

18. Smedly LA, Tonnesen MG, Sandhaus RA, Haslett C, Guthrie LA, Johnston RB, et al. Neutrophil-mediated injury to endothelial cells. Enhancement by endotoxin and essential role of neutrophil elastase. J Clin Invest. (1986) 77:1233-43. doi: 10.1172/JCI112426

19. Stamboul K, Zeller M, Rochette L, Cottin Y, Cochet A, Leclercq T, et al. Relation between high levels of myeloperoxidase in the culprit artery and microvascular obstruction, infarct size and reverse remodeling in ST-elevation myocardial infarction. PLOS ONE. (2017) 12:e017992912. doi: 10.1371/journal.pone.0179929

20. Vita JA, Brennan M-L, Gokce N, Mann SA, Goormastic M, Shishehbor $\mathrm{MH}$, et al. Serum myeloperoxidase levels independently predict endothelial dysfunction in humans. Circulation. (2004) 110:1134-39. doi: 10.1161/01.CIR.0000140262.20831.8F

21. Gupta AK, Joshi MB, Philippova M, Erne P, HASLER P, Hahn S, et al. Activated endothelial cells induce neutrophil extracellular traps and are susceptible to NETosis-mediated cell death. FEBS Lett. (2010) 584:31937. doi: $10.1016 /$ j.febslet.2010.06.006

22. Tayebi H, Kuttler F, Saaa P, Lienard A, Petracca B, Lapierre V, et al. Effect of granulocyte colony-stimulating factor mobilization on phenotypical and functional properties of immune cells. Exp Hematol. (2001) 29:45870. doi: 10.1016/S0301-472X(01)00613-0

23. Deotare U, Al-Dawsari G, Couban S, Lipton JH. G-CSF-primed bone marrow as a source of stem cells for allografting: revisiting the concept. Bone Marrow Transplant. (2019) 50:1150-6. doi: 10.1038/bmt.2 015.80 
24. Canales MA, Arrieta R, Gomez-Rioja R, Diez J, Jimenez-Yuste V, Hernandez-Navarro F. Induction of a hypercoagulability state and endothelial cell activation by granulocyte colony-stimulating factor in peripheral blood stem cell donors. J Hematother Stem Cell Res. (2002) 11:67581. doi: $10.1089 / 15258160260194820$

25. Gould TJ, Vu TT, Dwivedi DJ, Weitz JI, Liaw PC. Cell-free DNA modulates clot structure and impairs fibrinolysis in sepsis. J Throm Haemost. (2015) 13:341. doi: 10.1161/ATVBAHA.115.306035

26. Watt J, Ewart M-A, Greig FH, Oldroyd KG, Wadsworth RM, Kennedy S. The effect of reactive oxygen species on whole blood aggregation and the endothelial cell-platelet interaction in patients with coronary heart disease. Thromb Res. (2012) 130:210-5. doi: 10.1016/j.thromres.2012.03.024

27. Demers M, Krause DS, Schatzberg D, Martinod K, Voorhees JR, Fuchs TA, et al. Cancers predispose neutrophils to release extracellular DNA traps that contribute to cancer-associated thrombosis. Proc Natl Acad Sci USA. (2012) 109:13076-81. doi: 10.1073/pnas.1200419109

Conflict of Interest: The authors declare that the research was conducted in the absence of any commercial or financial relationships that could be construed as a potential conflict of interest.

Copyright $\odot 2020$ Stoikou, van Breda, Schäfer, Vokalova, Giaglis, Plattner, Infanti, Holbro, Hahn, Rossi and Buser. This is an open-access article distributed under the terms of the Creative Commons Attribution License (CC BY). The use, distribution or reproduction in other forums is permitted, provided the original author(s) and the copyright owner(s) are credited and that the original publication in this journal is cited, in accordance with accepted academic practice. No use, distribution or reproduction is permitted which does not comply with these terms. 